\title{
Poor glycaemic control is associated with reduced exercise performance and oxygen economy during cardio-pulmonary exercise testing in people with type 1 diabetes
}

Othmar Moser ${ }^{1,2^{*}}\left(\mathbb{D}\right.$, Max L. Eckstein 1,2, Olivia McCarthy ${ }^{1,2}$, Rachel Deere ${ }^{1,2}$, Stephen C. Bain ${ }^{1}$, Hanne L. Haahr ${ }^{3}$, Eric Zijlstra ${ }^{4}$ and Richard M. Bracken ${ }^{1,2}$

\begin{abstract}
Background: To explore the impact of glycaemic control $\left(\mathrm{HbA}_{1 \mathrm{c}}\right)$ on functional capacity during cardio-pulmonary exercise testing in people with type 1 diabetes.

Methods: Sixty-four individuals with type 1 diabetes (age: $34 \pm 8$ years; 13 females, $\mathrm{HbA}_{1}: 7.8 \pm 1 \%(62 \pm 13 \mathrm{mmol} /$ $\mathrm{mol})$, duration of diabetes: $17 \pm 9$ years) performed a cardio-pulmonary cycle ergometer exercise test until volitional exhaustion. Stepwise linear regression was used to explore relationships between $\mathrm{HbA}_{1 c}$ and cardio-respiratory data with $\mathrm{p} \leq 0.05$. Furthermore, participants were divided into quartiles based on $\mathrm{HbA}_{1 c}$ levels and cardio-respiratory data were analysed by one-way ANOVA. Multiple regression analysis was performed to explore the relationships between changes in time to exhaustion and cardio-respiratory data. Data were adjusted for confounder.

Results: $\mathrm{HbA}_{1 \mathrm{c}}$ was related to time to exhaustion and oxygen consumption at the power output elicited at the submaximal threshold of the heart rate turn point $\left(r=0.47, R^{2}=0.22, p=0.03\right)$. Significant differences were found at time to exhaustion between $\mathrm{Q} / \mathrm{vs}$. Q/V and at oxygen consumption at the power output elicited the heart rate turn point between Q/vs. Q// and Q/vs. Q/V ( $p<0.05)$. Changes in oxygen uptake, power output and in oxygen consumption at the power output elicited at the heart rate turn point and at maximum power output explained $55 \%$ of the variance in time to exhaustion $\left(r=0.74, R^{2}=0.55, p<0.01\right)$.
\end{abstract}

Conclusions: Poor glycaemic control is related to less economical use of oxygen at sub-maximal work rates and an earlier time to exhaustion during cardio-pulmonary exercise testing. However, exercise training could have the same potential to counteract the influence of poor glycaemic control on functional capacity.

Trial registration NCT01704417. Date of registration: October 11, 2012

Keywords: Glycaemic control, Exercise performance, Oxygen economy, Type 1 diabetes, Heart rate turn point

\section{Introduction}

Type 1 diabetes (T1D) is associated with an increased risk of cardio-vascular disease (CVD) compared to people without diabetes. Although regular physical activity

\footnotetext{
*Correspondence: Othmar.moser@swansea.ac.uk

${ }^{2}$ Applied Sport, Technology, Exercise and Medicine Research Centre

(A-STEM), College of Engineering, Swansea University, Fabian Way,

Crymlyn Burrows, Skewen, SA1 8EN Swansea, UK

Full list of author information is available at the end of the article
}

is encouraged as a cornerstone of good diabetes management [1, 2], physical inactivity rates remain high [3]. Patients often cite low functional capacity and loss of metabolic control (short-term and/or long term glycaemic disturbances) as barriers to beginning or maintaining regular physical activity [4].

Functional capacity, defined as the ability to perform aerobic work during maximal exercise testing can be assessed by means of cardio-pulmonary exercise (CPX) 
testing. This non-invasive, sensitive test provides an assessment of integrative responses of cardiovascular, pulmonary and musculoskeletal systems across a submaximal to maximal continuum and can be utilised to identify fatigue of cardiovascular or respiratory origin [5]. Most reported studies in people with T1D have assessed maximum cardio-pulmonary values such as the peak oxygen uptake $\left(\mathrm{VO}_{2 \text { peak }}\right)$ [6-8]. $\mathrm{VO}_{2 \text { peak }}$ is the highest rate of oxygen that can be consumed during exercise involving the majority of muscle mass at sea-level and is defined by the Fick equation as the product of cardiac output and arteriovenous oxygen difference [5]. Achieving a true $\mathrm{VO}_{2 \text { peak }}$ requires strong motivation and physical fitness, but for people with T1D with 'low exercise tolerance' the perception of exercise-induced pain may encourage premature test termination. In addition, the presence of diabetes complications such as neuropathy, nephropathy and underlying CVD may exacerbate pain or damage during exercise and reduce the validity of CPX testing in detailing accurate maximum cardio-respiratory parameters e.g. $\mathrm{VO}_{2}$ plateau, maximum heart rate $\left(\mathrm{HR}_{\max }\right)$.

Most activities in daily life are performed at low-to moderate intensity and do not require maximum cardiorespiratory effort. It may be more relevant in people with T1D to explore cardio-respiratory data obtained during sub-maximal stages of CPX testing. The rate of oxygen use at sub-maximal exercise intensities provides an indication of the economy of use of oxygen for an individual to the work rate and has been shown to predict endurance performance in healthy individuals [9]. Furthermore, identification of the sub-maximal work rate at which there is an increase in use of non-oxidative fuel sources (i.e. cellular glycolysis) results in a greater production of carbon dioxide $\left(\mathrm{CO}_{2}\right)$, pyruvate and lactic acid fermentation. Identification of such 'thresholds' involving ventilation, heart rate and/or blood lactate have been studied as sub-maximal predictors of endurance capacity in healthy cohorts and in people with chronic disease [5]. As an example the heart rate turn point (HRTP), which is based on findings from Conconi et al., was significantly associated with the second lactate threshold [10-13]. This heart rate derived threshold is defined as the intersection of two regression lines of the heart rate to performance curve between early stages of CPX testing [peri-first lactate turn point $\left.\left(\mathrm{LTP}_{1}\right)\right]$ and maximum power output $\left(\mathrm{P}_{\max }\right)$, determined from a second-degree polynomial representation satisfying the condition of least error squares [14]. However, there is a lack of information about their use in people with T1D in predicting functional capacity.

Lower maximum cardio-respiratory variables have been reported in participants with T1D compared to healthy individuals in some studies but not in others [8, 15]. A review by Baldi et al. [16] shed some light on the influence of glycaemic control within people with T1D and when compared to healthy individuals. Patients with poor glycaemic control demonstrated a lower peak functional capacity than those patients with good glycaemic control. No information currently exists on the influence of glycaemic control on sub-maximal cardio-respiratory parameters obtained from a CPX test. Such information might reveal additional insights on the impact of glycaemia on the functioning of the cardio-vascular and respiratory system and provide further support for the use of moderate intensity exercise tests that reduce stress on the patient.

The aim of this study was to examine the relationship of glycaemic control to sub-maximal and maximum cardiopulmonary markers obtained during CPX testing in people with T1D.

\section{Materials and methods \\ Participant characteristics}

Adults (aged 18-45 years, both inclusive) with T1D eligible for the study had a body mass index (BMI) of $18-27 \mathrm{~kg} / \mathrm{m}^{2}$, glycated haemoglobin $\left(\mathrm{HbA}_{1 \mathrm{c}}\right)$ level $\leq 9.5 \%$ $(80 \mathrm{mmol} / \mathrm{mol})$ and were performing regular physical cardiorespiratory exercise during the last 3 months before screening. Exclusion criteria included cancer, cardiac diseases, supine blood pressure outside the range $90-140 \mathrm{mmHg}$ for systolic blood pressure or 50-90 $\mathrm{mmHg}$ for diastolic blood pressure, recurrent severe hyperglycaemia or hypoglycaemia unawareness and smoking [17]. Sixty-four people with T1D were included for analyses (Table 1). Data were extracted from a clinical trial (NCT01704417) [17].

\section{Study procedures}

After the assessment of eligibility, patients were asked to fill in the International Physical Activity Questionnaire (IPAQ) to assess physical activity (MET min/week). Patients characteristics, medical history and medications were documented in a case report form (CRF). Afterwards, HbA1c was measured via a venous blood sample collected from the antecubital vein (Automated Glycohemoglobin Analyzer HLC-723G8, Tosoh Europe N.V, Belgium). Immediately before and after CPX testing, venous blood was collected to analyse blood glucose concentration to ensure euglycaemia during CPX testing (Super GL Glucose Analyzer, Dr. Müller Gerätebau GmbH, Germany). If pre-exercise venous blood glucose concentration was below $4.4 \mathrm{mmol} / \mathrm{l}$ carbohydrates were given (15-30 g) and if blood glucose concentration was above $13.9 \mathrm{mmol} / \mathrm{l}$ a small bolus correction dose was administered. No hypo- $(<3.9 \mathrm{mmol} / \mathrm{l})$ or severe hyperglycaemia 
Table 1 Participant characteristics given as mean \pm SD and percentage (\%)

\begin{tabular}{|c|c|}
\hline Characteristic & Total $(n=64)$ \\
\hline Age (years) & $34 \pm 8$ \\
\hline \multicolumn{2}{|l|}{ Gender } \\
\hline Female (n; \%) & $13(20)$ \\
\hline Male (n; \%) & $51(80)$ \\
\hline Body mass index $\left(\mathrm{kg} / \mathrm{m}^{2}\right)$ & $24 \pm 2$ \\
\hline Blood pressure $(\mathrm{mmHg})$ & $124 \pm 17 / 79 \pm 12$ \\
\hline Resting heart rate (b/min) & $81 \pm 12$ \\
\hline Duration of diabetes (years) & $17 \pm 9$ \\
\hline $\mathrm{HbA}_{1 \mathrm{c}}[\%(\mathrm{mmol} / \mathrm{mol})]$ & $7.8 \pm 1(62 \pm 13)$ \\
\hline Total daily dose of insulin (U) & $51 \pm 15$ \\
\hline \multicolumn{2}{|l|}{ Type of therapy } \\
\hline Multiple daily injections (n; \%) & $47(78)$ \\
\hline Insulin pump therapy (n; \%) & $17(22)$ \\
\hline Co-morbidities & 14 \\
\hline Arterial hypertension & 6 \\
\hline Hypothyroidism & 5 \\
\hline Hypercholesterolemia & 2 \\
\hline Hashimoto thyroiditis & 1 \\
\hline \multicolumn{2}{|l|}{ Medication other than insulin } \\
\hline ACE inhibitor & 6 \\
\hline Levothyroxine & 6 \\
\hline Statin & 2 \\
\hline Diuretic medication & 1 \\
\hline Calcium channel blocker & 1 \\
\hline Physical activity assessed via IPAQ (MET min week) & $3086 \pm 2736$ \\
\hline
\end{tabular}

(> 19.4 mmol/l) occurred before or during CPX testing. The timing of bolus insulin injection was not exactly pre-defined, but participants were told to avoid the peak action of bolus insulin during CPX testing (this means avoiding bolus insulin injections less than 120 min prior to the start of CPX testing). Participants performed a CPX test until volitional exhaustion on a cycle ergometer (Ergospirometer PowerCube ${ }^{\circledR}$-Ergo, Ganshorn Medizin Electronic, GER). Participants sat quietly on the cycle ergometer for $3 \mathrm{~min}(0 \mathrm{~W})$ before they started the warm-up period of $3 \mathrm{~min}$ cycling at a workload of $30 \mathrm{~W}$ for females and $40 \mathrm{~W}$ for males. Then, the workload was increased by $30 \mathrm{~W}$ for females and $40 \mathrm{~W}$ for males every 3 min until maximum volitional exhaustion. Finally, a cool-down period was performed for $1 \mathrm{~min}$.

\section{Measurements}

Pulmonary gas exchange variables were collected continuously by breath-by-breath measurement and then averaged over $10 \mathrm{~s}$. $\mathrm{VO}_{2 \text { peak }}$ was defined as the $1 \mathrm{~min}$ average in oxygen $\left(\mathrm{O}_{2}\right)$ consumption during the highest work rate. Heart rate and blood pressure were measured continuously via a 12-lead electrocardiogram and an automatic sphygmomanometer (Ergospirometer PowerCube ${ }^{\circledR}$-Ergo, Ganshorn Medizin Electronic, GER).

The non-invasive anaerobic threshold was defined by the HRTP [18]. HRTP was demarcated as the intersection of two regression lines of the heart rate to performance curve between post-warm-up and maximum power output $\left(\mathrm{P}_{\mathrm{max}}\right)$, determined from the second-degree polynomial representation satisfying the condition of least error squares [14]. Additionally, the second ventilatory threshold $\left(\mathrm{VT}_{2}\right)$ was determined by means of the ventilation/ carbon dioxide $\left(\mathrm{VE} / \mathrm{VCO}_{2}\right)$ slope [19] to control for the accuracy of HRTP.

\section{Statistical analysis}

Data (10 s average) were expressed as absolute values and relative to maximum physiological variables and $\mathrm{P}_{\max }$. Data were tested for distribution via Shapiro-Wilks normality test and non-normal distributed data were $\log$ transformed. Stepwise linear regression was used to explore relationships between glycaemic control $\left(\mathrm{HbA}_{1 \mathrm{c}}\right)$ and CPX obtained cardio-respiratory data and performance markers with $\mathrm{p} \leq 0.05$. Data were adjusted for sex, age, BMI, blood glucose concentration at the start of CPX testing and duration of diabetes. Post hoc power analysis for the primary outcome [stepwise linear regression: dependent variable $\mathrm{HbA}_{1 \mathrm{c}}$ levels, independent variables time to exhaustion ( Time $_{\text {max }}$ ) and oxygen economy at HRTP] resulted in a power (1-beta error probability) of 0.96 .

Participants were divided into quartiles $(\mathrm{Q})$ based on $\mathrm{HbA}_{1 \mathrm{c}}$ levels, and respective sub-maximal and maximal CPX derived cardio-respiratory data and performance markers were analysed by one-way analysis of variance (ANOVA) followed by a fishers least significant difference multiple comparison post hoc test (LSD). Multiple regression analysis was performed to explore relationships between changes in Time $_{\max }$ and independent variables, $\mathrm{VO}_{2 \text { peak }}$ and oxygen uptake at the heart rate turn point $\left(\mathrm{VO}_{2 \mathrm{HRTP}}\right)$, body mass adjusted values of $\mathrm{P}_{\max }$ and power output at the heart rate turn point $\left(\mathrm{P}_{\text {HRTP }}\right)$ as well as oxygen economy at $\mathrm{P}_{\max }\left[\mathrm{VO}_{2 \text { peak }} / \mathrm{P}_{\max }(\mathrm{ml} / \mathrm{min} / \mathrm{W})\right]$ and at HRTP $\left[\mathrm{VO}_{2 \text { HRTP }} / \mathrm{P}_{\text {HRTP }}(\mathrm{ml} / \mathrm{min} / \mathrm{W})\right]$. All statistics were performed with a standard software package of SPSS software version 22 (IBM Corporation, USA) and Prism Software version 7.0 (GraphPad, USA).

\section{Results}

\section{Exercise performance data}

Maximum physiological parameters were found at $\mathrm{HR}_{\max }$ of $185 \pm 11 \mathrm{~b} / \mathrm{min}, \mathrm{VO}_{2 \text { peak }} 37 \pm 5 \mathrm{ml} / \mathrm{kg} / \mathrm{min}$, respiratory exchange ratio (RER) $1.22 \pm 0.09$ and $\mathrm{P}_{\max } 231 \pm 47 \mathrm{~W}$. No significant differences were found between the HRTP 
and the $\mathrm{VT}_{2}$ as well as for the comparison of pre- and post-exercise blood glucose concentration as given in Table 2.

\section{Glycaemic control and functional capacity}

As shown in Fig. 1, sex-, age-, BMI-, blood glucose concentration at the start of CPX testing- and duration of diabetes-adjusted stepwise linear regression model revealed that $\mathrm{HbA}_{1 \mathrm{c}}$ was related to Time ${ }_{\max }$ and oxygen consumption at the power output elicited at the submaximal threshold of the heart rate turn point $\left(\mathrm{VO}_{2 \text { HRTP }} /\right.$ $\left.\mathrm{P}_{\text {HRTP }}\right)\left(\mathrm{r}=0.47, \mathrm{R}^{2}=0.22, \mathrm{p}=0.03\right)$.

\section{Grouped $\mathrm{HbA}_{1 \mathrm{c}}$ levels and functional capacity}

Grouping participants based on quartiles of glycaemic control resulted in $\mathrm{HbA}_{1 \mathrm{c}}$ levels of $6.7 \pm 0.5 \%$ $(49 \pm 6 \mathrm{mmol} / \mathrm{mol})$ for quartile $I, 7.6 \pm 0.1 \%$ $(60 \pm 1 \mathrm{mmol} / \mathrm{mol})$ for quartile $I I, 8.0 \pm 0.1 \%$ $(63 \pm 1 \mathrm{mmol} / \mathrm{mol}$ ) for quartile $I I I$ and $9.1 \pm 0.6 \%$ (76 $\pm 7 \mathrm{mmol} / \mathrm{mol})$ for quartile $I V(\mathrm{p}<0.01)$. No significant differences were found for physical activity $(\mathrm{p}=0.68)$, resting HR $(\mathrm{p}=0.42)$, systolic blood pressure $(\mathrm{p}=0.18)$ and diastolic blood pressure $(\mathrm{p}=0.83)$ between groups.
Significant differences were found at Time max $_{\text {max }}$ between $\mathrm{Q} I$ vs. $\mathrm{Q} I V$ (mean difference $2.5 \pm 1.0 \mathrm{~min}, \mathrm{p}=0.02)$ and at $\mathrm{VO}_{2 \mathrm{HRTP}} / \mathrm{P}_{\text {HRTP }}$ between $\mathrm{Q} I$ vs. $\mathrm{Q} I I(-1.5 \pm 0.6 \mathrm{ml} /$ $\mathrm{min} / \mathrm{W}, \mathrm{p}=0.02)$ and $\mathrm{Q} I$ vs $\mathrm{Q} I V(-1.6 \pm 0.71 \mathrm{ml} /$ $\min / \mathrm{W}, \mathrm{p}=0.01$ ) (Fig. 2).

White bar $=\mathrm{Q} I\left(\mathrm{HbA}_{1 \mathrm{c}} 6 . \pm 0.5 \% ; 4 \pm 6 \mathrm{mmol} /\right.$ mol), bright-grey bar $=\mathrm{Q} I I\left(\mathrm{HbA}_{1 \mathrm{c}} 7 . \pm 0.1 \%\right.$; $60 \pm 1 \mathrm{mmol} / \mathrm{mol})$, dark-grey bar $=\mathrm{Q} I I I\left(\mathrm{HbA}_{1 \mathrm{c}}\right.$ $8 . \pm 0.1 \% ; 6 \pm 1 \mathrm{mmol} / \mathrm{mol})$ and black bar $=\mathrm{Q} I V\left(\mathrm{HbA}_{1 \mathrm{c}}\right.$ $9.1 \pm 0.6 \% ; 7 \pm 7 \mathrm{mmol} / \mathrm{mol})$. Values are given as mean and SD. "“"” represents $\mathrm{p} \leq 0.05$.

Relationships of time to exhaustion and cardio-pulmonary responses during CPX testing

Multiple regression analysis revealed that changes in $\mathrm{VO}_{2 \text { peak }}, \mathrm{VO}_{2 \mathrm{HRTP}}, \mathrm{P}_{\text {max }}, \mathrm{P}_{\text {HRTP }}, \mathrm{VO}_{2 H R T P} / \mathrm{P}_{\text {HRTP }}$ as well as $\mathrm{VO}_{2 \text { peak }} / \mathrm{P}_{\max }$ constitute independent predictors of Time $_{\max }(r=0.74, \mathrm{p}<0.01)$ and those variables could explain $55 \%$ of the alteration in Time ${ }_{\max }$.

\section{Discussion}

This study demonstrated an important relationship between glycaemic control and the cardio-respiratory responses to CPX testing in people with T1D. Exercise

Table 2 Comparison of the anaerobic thresholds derived from HRTP and $\mathrm{VT}_{2}$ as well as pre- and post-exercise blood glucose levels

\begin{tabular}{llcc}
\hline & HRTP & VT $_{\mathbf{2}}$ & p value \\
\hline $\mathrm{VO}_{2}(\mathrm{I} / \mathrm{min})$ & $2.09 \pm 0.50$ & $2.17 \pm 0.50$ & 0.41 \\
$\mathrm{HR}(\mathrm{b} / \mathrm{min})$ & $158 \pm 14$ & $157 \pm 17$ & 0.63 \\
$\mathrm{P}(\mathrm{W})$ & $169 \pm 39$ & $172 \pm 38$ & 0.45 \\
$\mathrm{VE}(\mathrm{I} / \mathrm{min})$ & $55 \pm 13$ & $58 \pm 14$ & 0.26 \\
\hline & Pre-exercise & Post-exercise & p value \\
\hline $\mathrm{BG}(\mathrm{mmol} / \mathrm{l})$ & $9.3 \pm 3.4$ & $10 \pm 3.2$ & 0.06 \\
\hline
\end{tabular}

Results are given as mean \pm SD
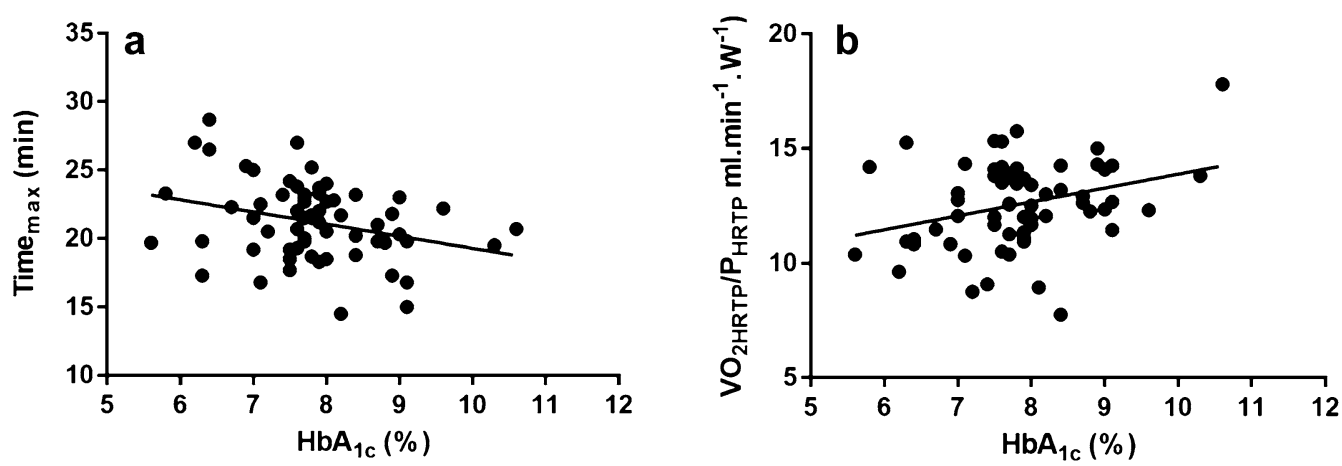

Fig. 1 Relationships between $\mathrm{HbA}_{1 \mathrm{c}}$ and $\mathbf{a}$ Time $_{\max }$ and $\mathbf{b} \mathrm{VO}_{2 \mathrm{HRTP}} / \mathrm{P}_{\mathrm{HRTP}} \mathrm{n}=64$ 


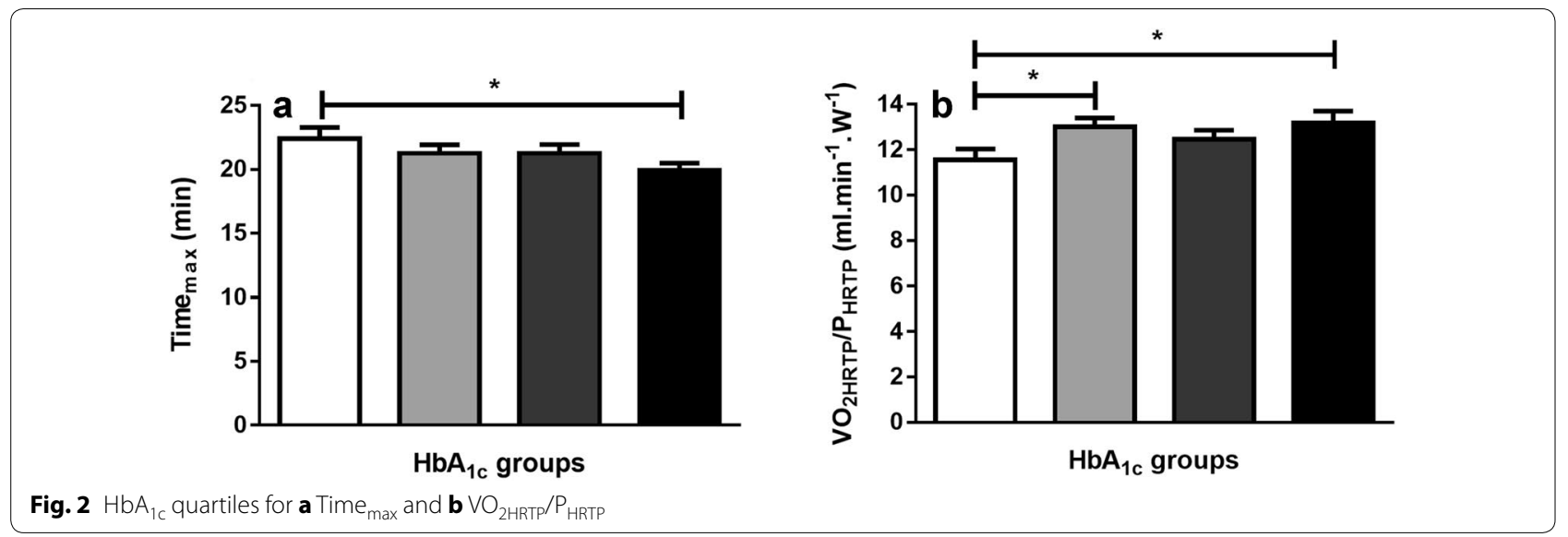

economy is defined as the rate of oxygen use at a given workload. We found that individuals with poorer glycaemic control (higher $\mathrm{HbA}_{1 \mathrm{c}}$ values) displayed a higher rate of $\mathrm{O}_{2}$ use at a sub-maximal work rate (HRTP) and ear-

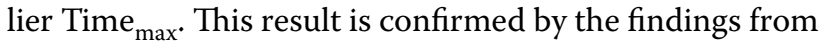
Tagougui et al. in which the increase in deoxyhemoglobin (reflection of relative tissue deoxygenation) in the vastus lateralis was blunted in patients with T1D and with poor glycaemic control during CPX testing [20]. Interestingly, the maximum oxygen consumption was negatively correlated with changes in deoxyhemoglobin.

Our findings are in contrast to recent studies evaluating the association between glycaemic control and functional capacity $[6,8]$. Stubbe et al. could not find an association between $\mathrm{HbA}_{1 \mathrm{c}}$ levels and the $\mathrm{O}_{2}$ uptake at the anaerobic lactate threshold [8]. This contrast in comparison to our results might explained by lower and more homogeneous $\mathrm{HbA}_{1 \mathrm{c}}$ levels as observed in our cohort. The variation in glycaemic control and its upper and lower extremes clearly contributed to the association between $\mathrm{HbA}_{1 \mathrm{c}}$ levels and rates of $\mathrm{O}_{2}$ use at the HRTP. Turinese et al. also did not find significant relationships between the glycaemic control and CPX derived markers [6]. However, the lack of associations might be originated by the low number of participants $(\mathrm{N}=17)$.

There may be several postulated reasons for our findings. During exercise, skeletal muscle consumes most of the inhaled $\mathrm{O}_{2}$ and a greater $\mathrm{O}_{2}$ cost for a given exercise intensity might indicate fibre atrophy and/or morphological abnormalities in the mitochondria [21]. Reduced skeletal muscle mitochondrial ATP production rates have also been associated with poor glycaemic control [22]. Furthermore, the capillary density surrounding skeletal muscle has been shown to be lower in individuals with T1D [23]. A reduced oxidative capacity within prime mover muscles increases dependence on supporting muscles, and increases the overall oxygen cost of the activity for a given workload. Furthermore, an earlier limit on $\mathrm{O}_{2}$ use within a muscle shifts energy metabolism towards non-oxidative glycolysis and an earlier lowered $\mathrm{pH}$ [24]. Alternatively, oxygen supply systems may be compromised more in individuals with poorer glycaemic control. Red blood cell dynamics have been shown to be altered in T1D rats [25] with velocity and flux reduced in comparison to non-diabetics, albeit with a similar haematocrit.

People with T1D may display cardiomyopathy and this seems dependent on the $\mathrm{HbA}_{1 \mathrm{c}}$ value which has been hypothesised to alter cardiac structure, e.g. increased left ventricular wall thickness and mass, and impaired diastolic function. Interestingly, poor glycaemic control was associated with reduced stroke volume and cardiac output in athletes with T1D compared with non-diabetic individuals, despite an equivalent amount of training [26]. This reduction in stroke volume might be caused by earlier diastolic dysfunction, which reduces the atrioventricular pressure gradient and causes early diastolic left ventricular filling [16].

The decreased economy at early stages during CPX testing translated to shorter exercise test duration. Indeed, approximately $55 \%$ of the shorter total exercise time could be accounted for lowered $\mathrm{O}_{2}$ uptake, decreased power output and less economical use of $\mathrm{O}_{2}$ for both at the HRTP and maximum power. Taken this into account, it might be that regular exercise training, which increases these physiological parameters, might have similar potential to neutralise the negative influence of glycaemic control on functional capacity [27] and even on cardiovascular autonomic regulation [28].

This study is limited by the heterogeneity and the wide range in the duration of diabetes, age, blood glucose concentration at the start of CPX testing and sex distribution. However, we addressed this limitation as we have adjusted for these factors. Additionally, it might be that different levels of blood glucose influenced 
catecholamine response which in turn altered cardiac function during CPX testing.

\section{Conclusions}

In conclusion, in this well-characterised study, individuals with T1D and poorer glycaemic control displayed less economical use of oxygen at sub-maximal work rates and an earlier time to exhaustion during CPX testing. Nevertheless, exercise training could have the same potential to counteract the influence of poor glycaemic control on functional capacity.

\begin{abstract}
Abbreviations
T1D: type 1 diabetes; CVD: cardio-vascular disease; CPX: cardio-pulmonary exercise; $\mathrm{VO}_{2 \text { peak: }}$ : peak oxygen uptake; $\mathrm{HR}_{\text {max }}$ : maximum heart rate; $\mathrm{CO}_{2}$ : carbon dioxide; HRTP: heart rate turn point; $L$ LP $_{1}$ : first lactate turn point; $P_{\max }$ : maximum power output; IPAQ: International Physical Activity Questionnaire; VT2: second ventilatory; $\mathrm{VE} / \mathrm{VCO}_{2}$ slope: ventilation/carbon dioxide slope; BMI: body mass index; $\mathrm{HbA}_{1}$ : glycated haemoglobin; $\mathrm{O}_{2}$ : oxygen; Q: quartiles; ANOVA: analysis of variance; LSD: fishers least significant difference multiple comparison post hoc test; Time max : time to exhaustion; $\mathrm{VO}_{2 \text { HRTP }}$ : oxygen uptake at the heart rate turn point; $\mathrm{P}_{\mathrm{HRT}}$ : power output at the heart rate turn point; RER: respiratory exchange ratio; $\mathrm{HR}_{\mathrm{HRTP}}$ : heart rate at the heart rate turn point.
\end{abstract}

\section{Authors' contributions}

$\mathrm{OM}, \mathrm{RMB}, \mathrm{EZ}, \mathrm{SCB}$ and HLH designed the study. EZ supervised exercise testing. $O M, R M B, M L E, O M C$ and $R D$ analysed and interpreted the data. OM, RMB and SCB wrote the first draft of the paper. EZ, MLE, OMc, RD and HLH edited the paper. All authors contributed to the writing of the paper. All authors read and approved the final manuscript.

\section{Author details \\ 1 Diabetes Research Group, Medical School, Swansea University, SA2 8 PP Swansea, UK. ${ }^{2}$ Applied Sport, Technology, Exercise and Medicine Research Centre (A-STEM), College of Engineering, Swansea University, Fabian Way, Crymlyn Burrows, Skewen, SA1 8EN Swansea, UK. ${ }^{3}$ Novo Nordisk A/S, Vandtårnsvej 108, 2860 Søborg, Denmark. ${ }^{4}$ Profil, Hellenbergsstraße 9, 41460 Neuss, Germany.}

\section{Acknowledgements}

Data were extracted from a clinical trial (NCT01704417).

\section{Competing interests}

OM has received lecture fees from Medtronic and received a grant from Sêr Cymru II COFUND fellowship/European Union. MLE has received a KESS2/ European Social Fund scholarship. SCB reports having received honoraria, teaching and research grants from the Abbott, Astra Zeneca, Boehringer Ingelheim, BMS, Diartis, Eli Lily and Company, GlaxoSmithKline, Johnson \& Johnson, Merck Sharp\& Dohme, Novartis, Novo Nordisk, Pfizer, Roche, Sanofi-Aventis, Schering-Plough, Servier and Takeda. RMB reports having received honoraria, travel and educational grant support from, Boehringer-Ingelheim, Eli Lily and Company, Novo Nordisk, Sanofi-Aventis. EZ, RD and OMc have no disclosures to report. HLH is employee and shareholder in Novo Nordisk A/S.

\section{Availability of data and materials}

The datasets used and/or analysed during the current study are available from the corresponding author on reasonable request.

\section{Consent for publication}

Informed consent for publication was obtained before any trial related activities.

\section{Ethics approval and consent to participate}

All procedures performed were in accordance with Good Clinical Practice (GCP) the ethical standards of the national research committee and with the 1964 Helsinki Declaration and its later amendments. The study protocol was approved by an independent ethics committee (Ethikkommission der Ärztekammer Nordrhein; Reference Number: 2012269). Written informed consent was obtained before any trial related activities.

\section{Funding}

The study was sponsored by Novo Nordisk A/S. Novo Nordisk A/S contributed only as a sponsor for this trial.

\section{Publisher's Note}

Springer Nature remains neutral with regard to jurisdictional claims in published maps and institutional affiliations.

Received: 3 October 2017 Accepted: 15 November 2017

Published online: 21 November 2017

\section{References}

1. Riddell MC, Gallen IW, Smart CE, et al. Exercise management in type 1 diabetes: a consensus statement. Lancet Diabetes Endocrinol. 2017;8587:114. https://doi.org/10.1016/S2213-8587(17)30014-1.

2. Codella R, Terruzzi I, Luzi L. Why should people with type 1 diabetes exercise regularly? Acta Diabetol. 2017;54:615-30. https://doi.org/10.1007/ s00592-017-0978-X.

3. Plotnikoff RC, Taylor LM, Wilson PM, et al. Factors associated with physical activity in Canadian adults with diabetes. Med Sci Sports Exerc. 2006;38:1526-34. https://doi.org/10.1249/01.mss.0000228937.86539.95.

4. Brazeau AS, Rabasa-Lhoret R, Strychar IMH. Barriers to physical activity among patients With type 1 diabetes. Diabetes Care. 2008;31:2108-9. https://doi.org/10.2337/dc08-0720.

5. Balady GJ, Arena R, Sietsema K, et al. Clinician's guide to cardiopulmonary exercise testing in adults: a scientific statement from the American heart association. Circulation. 2010;122:191-225. https://doi.org/10.1161/ CIR.0b013e3181e52e69.

6. Turinese I, Marinelli P, Bonini M, et al. Metabolic and cardiovascular response to exercise in patients with type 1 diabetes. J Endocrinol Invest. 2017. https://doi.org/10.1007/s40618-017-0670-6.

7. Gusso S, Pinto TE, Baldi JC, et al. Diastolic function is reduced in adolescents with type 1 diabetes in response to exercise. Diabetes Care. 2012;35:2089-94. https://doi.org/10.2337/dc11-2331.

8. Stubbe B, Schipf S, Schäper C, et al. The influence of type 1 diabetes mellitus on pulmonary function and exercise capacity - results from the study of health in pomerania (SHIP). Exp Clin Endocrinol Diabetes. 2017;125:64-9. https://doi.org/10.1055/s-0042-112219.

9. Yoshida T, Udo M, Iwai K, Yamaguchi T. Physiological characteristics related to endurance running performance in female distance runners. $J$ Sports Sci. 1993;11:57-62. https://doi.org/10.1080/02640419308729964.

10. Conconi F, Ferrari M, Ziglio PG, et al. Determination of the anaerobic threshold by a noninvasive field test in runners. J Appl Physiol. 1982;52:869-73.

11. Ribeiro JP, Fielding RA, Hughes V, et al. Heart rate break point may coincide with the anaerobic and not the aerobic threshold. Int I Sports Med 1985;6:220-4. https://doi.org/10.1055/s-2008-1025844.

12. Hofmann $P$, Bunc $V$, Leitner $H$, et al. Heart rate threshold related to lactate turn point and steady-state exercise on a cycle ergometer. Eur J Appl Physiol Occup Physiol. 1994;69:132-9.

13. Bunc V, Hofmann P, Leitner H, Gaisl G. Verification of the heart rate threshold. Eur J Appl Physiol Occup Physiol. 1995;70:263-9.

14. Hofmann P, Pokan R, Duvillard S, et al. Heart rate performance curve during incremental cycle ergometer exercise in healthy young male subjects. Med Sci Sport Exerc. 1997;195:762-8.

15. Veves A, Saouaf R, Donaghue VM, et al. Aerobic exercise capacity remains normal despite impaired endothelial function in the micro- and macrocirculation of physically active IDDM patients. Diabetes. 1997;46:1846-52.

16. Baldi JC, Hofman PL. Does careful glycemic control improve aerobic capacity in subjects with type 1 diabetes? Exerc Sport Sci Rev. 2010;38:161-7. https://doi.org/10.1097/JES.0b013e3181f4501e. 
17. Heise T, Bain SC, Bracken RM, et al. Similar risk of exercise-related hypoglycaemia for insulin degludec to that for insulin glargine in patients with type 1 diabetes: a randomized cross-over trial. Diabetes Obes Metab. 2016;18:196-9. https://doi.org/10.1111/dom.12588.

18. Beckers PJ, Possemiers NM, Van Craenenbroeck EM, et al. Comparison of three methods to identify the anaerobic threshold during maximal exercise testing in patients with chronic heart failure. Am J Phys Med Rehabil. 2012;91:148-55. https://doi.org/10.1097/PHM.0b013e3182411d69.

19. Wasserman K, Whipp BJ, Davis JA. Respiratory physiology of exercise: metabolism, gas exchange, and ventilatory control. Int Rev Physiol. 1981;23:149-211.

20. Tagougui S, Leclair E, Fontaine $P$, et al. Muscle oxygen supply impairment during exercise in poorly controlled type 1 diabetes. Med Sci Sports Exerc. 2015;47:231-9. https://doi.org/10.1249/MSS.0000000000000424.

21. Reske-Nielsen E, Harmsen A, Vorre P. Ultrastructure of muscle biopsies in recent, short-term and long-term juvenile diabetes. Acta Neurol Scand. 1977;55:345-62.

22. Karakelides H, Asmann YW, Bigelow ML, et al. Effect of insulin deprivation on muscle mitochondrial ATP production and gene transcript levels in type 1 diabetic subjects. Diabetes. 2007;56:2683-9.

23. Krause MP, Riddell MC, Hawke TJ. Effects of type 1 diabetes mellitus on skeletal muscle: clinical observations and physiological mechanisms. Pediatr Diabetes. 2011;12:345-64. https://doi. org/10.1111/j.1399-5448.2010.00699.x.

24. Crowther GJ, Milstein JM, Jubrias SA, et al. Altered energetic properties in skeletal muscle of men with well-controlled insulin-dependent (type 1) diabetes. Am J Physiol Endocrinol Metab. 2003;284:E655-62. https://doi. org/10.1152/ajpendo.00343.2002.

25. Kindig CA, Sexton WL, Fedde MR, Poole DC. Skeletal muscle microcirculatory structure and hemodynamics in diabetes. Respir Physiol. 1998;111:163-75. https://doi.org/10.1016/S0034-5687(97)00122-9.

26. Baldi JC, Cassuto NA, Foxx-Lupo WT, et al. Glycemic status affects cardiopulmonary exercise response in athletes with type I diabetes. Med Sci Sports Exerc. 2010;42:1454-9. https://doi.org/10.1249/ MSS.0b013e3181d1fdb3.

27. Gusso S, Pinto T, Baldi JC, et al. Exercise training improves but does not normalize left ventricular systolic and diastolic function in adolescents with type 1 diabetes. Diabetes Care. 2017. https://doi.org/10.2337/ dc16-2347.

28. Lucini D, Zuccotti GV, Scaramuzza A, et al. Exercise might improve cardiovascular autonomic regulation in adolescents with type 1 diabetes. Acta Diabetol. 2013;50:341-9. https://doi.org/10.1007/s00592-012-0416-z.

\section{Submit your next manuscript to BioMed Central and we will help you at every step:}

- We accept pre-submission inquiries

- Our selector tool helps you to find the most relevant journal

- We provide round the clock customer support

- Convenient online submission

- Thorough peer review

- Inclusion in PubMed and all major indexing services

- Maximum visibility for your research

Submit your manuscript at www.biomedcentral.com/submit
() Biomed Central 